\title{
Correção gramatical e clareza afetam a qualidade do texto científico?
}

\author{
TARCISO S. FILGUEIRAS ${ }^{1}$
}

(recebido: 22 de julho de 2010; aceito: 26 de agosto de 2010)

\begin{abstract}
Do grammatical correctness and clarity compromise the quality of scientific papers?). The style of a scientific paper differs markedly from a text of non scientific literature. The style in scientific writing is simple, direct and should closely adhere to the standard grammatical rules. Articles in botany and plant ecology published in Portuguese in Brazil in the last decade frequently present certain recurrent grammatical improprieties that must be addressed to because they compromise the final quality of the paper. It is suggested here that the scientific periodicals in Brazil should have professional reviewers of the Portuguese language in their editorial board because this will not only improve the final quality of the papers but will also release the peers to focus on the quality of the scientific and technical contents of the manuscript and not on linguistic problems.
\end{abstract}

Key words - editorial policy, Portuguese in botanical publications, Portuguese in plant ecology publications, scientific writing

RESUMO - (Correção gramatical e clareza afetam a qualidade do texto científico?). O texto científico é distinto do texto literário, do qual se originou. Este deve ser enxuto, despojado e aderir totalmente às normas da gramática normativa. No entanto, isto nem sempre acontece. Artigos nas áreas de Botânica e Ecologia Vegetal, publicados na última década no Brasil, frequentemente, apresentam certas incorreções gramaticais recorrentes que devem ser enfrentadas pois elas afetam a qualidade final do trabalho. Sugere-se que os periódicos nacionais devam ter revisores profissionais em seu corpo editorial. Isto contribuirá para elevar a qualidade dos textos publicados, permitirá que o consultor ad hoc concentre-se no conteúdo técnico e científico do manuscrito, além de desobrigá-lo de emitir opinião sobre uma área que não é sua especialidade, a língua portuguesa.

Palavras-chave - política editorial, português nas publicações botânicas, português nas publicações em ecologia vegetal, redação científica

\section{Introdução}

O texto científico (TC) originou-se do texto literário (TL). Antes que o TC adquirisse características próprias, os dois estilos se confundiam e se influenciavam, pois não havia uma clara divisão entre eles. No passado, quem escrevia sobre ciência, fazia-o de maneira "literária" e, às vezes, até poética, com o intuito de mostrar erudição. Porém, à medida que a ciência se separava da filosofia e fincava os pés na observação objetiva da natureza, na análise criteriosa dos fenômenos e na experimentação, o TC, aos poucos, se libertou de adereços literários, despojou-se até atingir a forma atual onde não se admite qualquer divagação que não tenha relação direta com o tema abordado. O TC contemporâneo é, idealisticamente falando, enxuto, escrito em linguagem correta, só tem carne e osso, não tem gordura nem pelancas e proclama adesão total à norma culta da língua.

Isto em teoria. A realidade mostra artigos científicos com erros gramaticais, parágrafos demasiadamente

1. Instituto de Botânica, Núcleo de Pesquisa em Taxonomia de Fanerógamas, Caixa Postal 3005, 01031-970 São Paulo, SP, Brasil (tfilg@uol.com.br). longos, confusos, sem ideia central, ou pior, contendo várias ideias paralelas e conflitantes.

A produção cientifica nacional cresceu enormemente nas últimas décadas, tanto em quantidade quanto em qualidade. Este fato deve ser reconhecido e celebrado. Contudo, especialmente para quem escreve em língua portuguesa, a qualidade dos textos produzidos no Brasil ainda tem um longo caminho a percorrer. A adesão à chamada 'norma culta' é um dever de quem escreve em português. Em geral, o pesquisador brasileiro não tem o hábito de consultar gramáticas, muito menos de procurar boas fontes de referência sobre regência verbal e nominal.

Regência verbal? Regência nominal? Isto morde? Não, mas se não forem observadas, podem comprometer o texto, tornando-o ambíguo e sujeito a mais de uma interpretação. É fato notório que alguns pesquisadores brasileiros, quando escrevem em inglês, empenham-se em produzir um texto correto e claro, recorrendo, quando necessário, a parcerias ou a serviços profissionais especializados. No entanto, quando escrevem em português, fazem-no de modo casual e até desleixado. Existem cientistas brasileiros que escrevem bem em inglês, porém escrevem mediocremente na língua pátria. 


\section{Situações recorrentes}

Quem acompanha, com olhar crítico, a produção científica nacional na última década nas áreas de Botânica e Ecologia Vegetal, se surpreende com a recorrência de situações gramaticais claramente criticáveis sob o ponto de vista formal. Algumas dessas situações serão comentadas a seguir, com proposital omissão da fonte, pois o que interessa é o fato e não a autoria.

Voz passiva - Este é um tópico sensível nos textos científicos publicados em português. Se não for empregada com conhecimento de causa, esta voz pode provocar barulho ensurdecedor no TC. A gramática ensina que a voz passiva pode se apresentar sob duas formas, analítica e sintética ou pronominal. O primeiro caso é corriqueiro e não traz dificuldades, pois é formado pelos verbos ser, estar, ficar, mais o particípio. Exemplo: "Os dados foram analisados pelo programa Dallas". Já o segundo caso, que se obtém através do apassivador "se", requer mais cuidado, pois é necessário ter clareza de qual palavra ou expressão exerce o papel de sujeito da oração. Exemplo: "Coletou-se cinco espécimes de cada espécie" ou "coletaram-se cinco espécimes de cada espécie"? Acertou quem escreveu "coletaram-se" já que a função de sujeito é exercida pela expressão "cinco espécimes". Se isto soar estranho, basta mudar para a forma analítica, obtendo-se, então, "foram coletados cinco espécimes". Isto posto, já não se aceitam expressões como "retirou-se duas subamostras" ou "utilizou-se dois índices" ["retiram-se duas subamostras" ou "duas subamostras foram retiradas"; utilizaram-se dois índices" ou "dois índices foram utilizados"].

As construções com o apassivador "se" são de uso corrente em textos acadêmicos, onde se tornam muito úteis, resultando parágrafos mais enxutos. No entanto, se o autor achar que o resultado soa um tanto pedante ("fizeram-se cinco ensaios"), seria melhor utilizar a velha forma analítica ("Foram feitos cinco ensaios").

Situação semelhante ocorre com a expressão "trata-se de". "Trata-se de caracteres relictuais" ou "tratam-se de caracteres relictuais"? A presença da preposição "de" torna esta expressão invariável. Portanto, acertou quem escreveu "trata-se de caracteres relictuais". Igualmente, acertou quem escreveu "trata-se de espécies raras, merecedoras de atenção do poder público".

Contração da preposição de - Dificuldades no uso correto da contração da preposição "de" com artigos, pronomes, etc., são também fontes de deslizes gramaticais em textos científicos. Na contração, ocorre a redução de uma $\operatorname{vogal}(\mathrm{de}+\mathrm{a}=\mathrm{da}$, de + este $=$ deste, etc. $)$. Segundo os gramáticos, não se deve usar a contração quando o de for parte integrante do sintagma nominal. Portanto, "Antes de os dados serem analisados" e não "Antes dos dados serem analisados", "Apesar de a biomassa de folhas ter apresentado comportamento diverso" e não "Apesar da biomassa de folhas ter apresentado comportamento diverso".

É forçoso admitir que as duas formas são muito semelhantes e que a distinção entre elas só se torna evidente com a leitura contínua de bons texto, com o apuro auditivo e prática da boa escrita. Contudo, a atenção a este detalhe demonstra domínio linguístico e refinamento gramatical.

Regência verbal e nominal - São tópicos difíceis da gramática normativa. A complexidade da língua permite regências distintas para o mesmo verbo ou substantivo. A única maneira de se ter certeza de que não se incorre em erro é a consulta constante a fontes confiáveis, ou seja, autores de reconhecida reputação na área. Alguns verbos são transitivos diretos e não admitem qualquer preposição, ao passo que outros, ao contrário, requerem a presença obrigatória da preposição e, mais que isto, de determinada preposição. Nestas circunstâncias, é necessário verificar caso a caso. O verbo 'implicar' é um bom exemplo. As gramáticas mais antigas admitem a regência com a preposição 'em', enquanto que as mais modernas e os manuais de estilo recomendam o seu uso sem preposição. Portanto, está com a tradição quem escreveu "aceitar este raciocínio implica em rejeitar um pressuposto fundamental do pensamento cladístico". Porém alia-se com a contemporaneidade quem escreveu "preservar esta espécie implica criar uma nova unidade de conservação na Caatinga".

Períodos longos $\times$ períodos curtos - Ambos são necessários e ambos podem ser usados, de acordo com as circunstâncias, pois não existe tamanho ideal para o parágrafo. No entanto, no TC emprega-se, mais frequentemente, o parágrafo de tamanho médio, que encerra somente uma idéia principal e não mescla assuntos distintos. Sempre que o autor notar que seu parágrafo ficou excessivamente longo, deve voltar a analisá-lo e, se for o caso, desdobrá-lo em dois ou três menores, por questões de clareza. No extremo oposto, encontra-se o período demasiadamente curto, no estilo "conta-gota" em que o autor vai pingando as informações de maneira cansativa para o leitor. Claramente, este também deve ser evitado.

\section{Considerações finais}

Devido ao nível de excelência que muitos periódicos brasileiros alcançaram nas ultimas décadas, torna-se 
necessário que eles se tornem mais profissionais no processamento final dos textos, antes da publicação. Os periódicos científicos devem agregar a seu Corpo Editorial revisores profissionais que escrutinem o texto para obter um alto nível nas publicações. Estes revisores apenas atuariam depois que o texto fosse aprovado pelas comissões preliminares e pelos revisores ad hoc. Em termos populares, eles passariam um "pente fino" em todo o texto, já totalmente revisto em seu conteúdo técnico e científico. Os custos desta inovação deveriam ser assumidos pelos órgãos de fomento, pois é de seu interesse elevar, cada vez mais, a qualidade da produção científica no país.
Ao adotar esta nova política editorial, os periódicos não somente elevariam a qualidade do TC produzido no Brasil como também desobrigariam o consultor ad hoc de atuar em uma área que não é sua especialidade, a língua portuguesa. $O$ consultor seria aconselhado a concentrar-se nos aspectos técnicos e científicos do manuscrito a ser analisado. Isto, aliás, já é prática corrente nos periódicos de maior reputação fora do Brasil. Um consultor ad hoc de um periódico internacional considerado pela comunidade cientifica como "Qualis A", não deve se preocupar com a parte formal do manuscrito. Isto será um trabalho posterior, especializado, caso o texto seja aprovado sob o ponto de vista estritamente científico. Este bom exemplo deve ser imitado no Brasil. 